\title{
Comissão Própria de Avaliação - CPA: sua atuação na construção do diálogo entre comunidade acadêmica e direção da IES
}

Own Evaluation Committee - CPA: its action in construction of the dialogue between the academic community and IES directors

Renato de Oliveira Brito ${ }^{1}$

Alexandre Anselmo Guilherme ${ }^{2}$

Luiz César Córdoba ${ }^{3}$

Alessandra Freire Magalhães de Campos ${ }^{4}$

Resumo O presente artigo, baseado em pesquisa exploratória de natureza quali-quanti realizada em centros universitários privados do DF, busca investigar a efetividade da Comissão Própria de Avaliação na construção do processo dialógico entre a comunidade acadêmica e a direção das IES. Propõe-se a aproximação entre o conceito do diálogo ao papel da autoavaliação institucional conduzida pela CPA. Os resultados apontam que, dentro da concepção emancipatória e sistêmica de avaliação proposta pelo SINAES, a atuação da CPA pode construir vinculação entre os instrumentos de informação e o planejamento estratégico das IES.

Palavras-chave: Autoavaliação institucional. Comissão Própria de Avaliação (CPA). Diálogo. 
Abstract: This article, based on exploratory research of a quali-quanti nature conducted in private university centers of the Federal District, seeks to investigate the effectiveness of the Own Evaluation Committee in constructing the dialogical process between the academic community and the direction of the HEI. It is proposed to approximate the concept of dialogue to the role of institutional self-assessment conducted by the CPA. The results point that, within the emancipatory and systemic conception of evaluation proposed by SINAES, the performance of the CPA can build links between the information instruments and the strategic planning.

Keywords: Institutional Self-Evaluation. Own Evaluation Committee (CPA); Dialogue.

${ }^{1}$ Universidade Católica de Brasília | Programa de pós-graduação Stricto Sensu em Educação |Brasília | DF | Brasil. Contato: renatoorios@gmail.com. ORCID: http://orcid.org/0000-0002-9345-2529.

${ }^{2}$ Pontifícia Universidade Católica do Rio Grande do Sul | Escola de Humanidades | Programa de pósgraduação Stricto Sensu em Educação | Porto Alegre | RS | Brasil.

Contato: alexandre.guilherme@ pucrs.br. ORCID: http://orcid.org/0000-0003-4578-1894.

${ }^{3}$ Universidade Católica de Brasília | Programa de pós-graduação Stricto Sensu em Educação | Brasília | DF | Brasil. Contato: contato@ cordoba.pro.br. ORCID: https://orcid.org/0000-0001-9406-9604.

${ }^{4}$ Universidade Católica de Brasília | Programa de pós-graduação Stricto Sensu em Educação | Brasil. Contato: ale.fmcampos@gmail.com. ORCID: https://orcid.org/0000-0002-1129-9824.

- Recebido em: 27 de outubro de 2019

- Aprovado em: 8 de junho de 2020

DOI: http://dx.doi.org/10.1590/S1414-40772021000100005

Este é um artigo publicado em acesso aberto sob uma licença Creative Commons https://creativecommons.org/licenses/by-nc/4.0/ 


\section{Introdução}

Estudos sobre as teorias das organizações educativas revelam que ainda são escassas as contribuições das pesquisas sobre a administração educacional para as teorias das organizações e da administração em geral (DINIS, 2015). Nessa perspectiva, considera-se fundamental que a academia possa contribuir com estudos que possibilitem o enriquecimento desse referencial científico, lançando um olhar cuidadoso e direcionado a tal realidade, tendo em vista a especificidade de estrutura, organização e funcionamento das instituições educativas. Assim sendo, nas últimas décadas do século $\mathrm{XX}$, vários fatores e contextos impulsionaram as pesquisas na área da gestão/administração escolar/educacional por parte da comunidade acadêmica, conforme descreve Sander (2007). Entretanto, apesar da propagação de artigos, dissertações e teses atinentes à administração da educação a partir desse período, ainda se verifica vasto campo para os estudos referentes à gestão educacional.

Mais especificamente e dentre as diversas, complexas e importantes temáticas que permeiam o campo de gestão educacional, a avaliação da educação superior tem ocupado, nas últimas décadas, posição privilegiada, devido ao financiamento público de algumas instituições como também ao papel central que estas assumem no modelo econômico-social decorrente dos fenômenos de mundialização e de globalização (BARREYRO; ROTHEN, 2006). Isto tem encorajado discussões sobre transparência e boas práticas, bem como levado a noções mais pragmáticas de 'review and development' (quer dizer, 'avaliação e desenvolvimento').

A partir dessas considerações gerais, passamos a concentrar o debate da avaliação da educação superior, proposto neste estudo, no recorte ocupado pela autoavaliação institucional conduzida Comissão Própria de Avaliação - CPA, cuja constituição e finalidade encontram-se estabelecidas na Lei No 10.861/2004 (BRASIL, 2004), que instituiu o Sistema Nacional de Avaliação da Educação Superior - SINAES.

Vale notar que, muito embora a exigência para criação de uma Comissão Própria de Avaliação - CPA seja de caráter legal/regulatório para as Instituições de Ensino Superior - IES, sua função pode superar a mera coleta de dados e pesquisas junto à comunidade acadêmica. De fato, argumentamos que a CPA pode assumir um papel fundamental na construção do diálogo entre a direção da IES e a comunidade acadêmica, o que pode ser feito, for exemplo, através da noção de 'review and development'. Sendo assim, neste estudo, propomos lançar luz sobre a atuação da CPA na construção do processo dialógico entre a direção da IES e sua comunidade acadêmica. Se, para além do acompanhamento e/ou execução, a comunidade acadêmica pode contribuir com a elaboração dos objetivos do planejamento, tanto maior será a chance de se 
alcançar a satisfação destes, na medida em que percebem atendidas as suas demandas apontadas nas pesquisas promovidas pela CPA.

O presente trabalho foi organizado em duas partes. A primeira apresenta breve contextualização da avaliação da educação superior no Brasil e do papel da autoavaliação institucional e da CPA na perspectiva emancipatória e dialógica da avaliação para a comunidade acadêmica e a gestão. A segunda parte consiste na análise da pesquisa empírica realizada com representantes da CPA de centros universitários privados do Distrito Federal.

Nesse contexto, a presente pesquisa foi realizada por meio de entrevista semiestruturada junto às coordenações da CPA de dois centros universitários e pela estatística descritiva das respostas de 32 respondentes a questionário, participantes da CPA de um total de seis IES do DF. O campo de pesquisa limitou-se a IES privadas do Distrito Federal, mais especificamente a centros universitários, uma vez que, além da atividade de ensino, atuam também nas atividades de iniciação científica e extensão, espaços próprios ao maior envolvimento da comunidade acadêmica e, portanto, mais propícios ao surgimento de demandas para diálogos. Este trabalho busca investigar, portanto, a efetividade da Comissão Própria de Avaliação - CPA como agente articulador e promotor da construção do processo dialógico entre a comunidade acadêmica e a direção das IES.

\section{Breves reflexões sobre a avaliação do ensino superior no Brasil}

No final do século XX, o sistema de educação superior brasileiro passou por uma expansão desordenada, com aumento indiscriminado de matrículas e de instituições de ensino sem, necessariamente, garantir a democratização do acesso e assegurar a permanência dos alunos e a qualidade do processo (ZAINKO, 2008).

Tal crescimento indiscriminado chamou a atenção de gestores e formuladores de políticas educacionais quanto à necessidade de recorrer a instrumentos de avaliação que possibilitassem garantir parâmetros de qualidade relacionados a critérios científicos e acadêmicos internacionais, bem como às demandas de formação profissional dos estudantes, como ressalta Peixoto (2009). A avaliação passou, assim, a ganhar notoriedade no cenário da educação superior, atraindo a atenção da sociedade e destacando-se na pauta política.

Segundo Peixoto (2009), esse momento suscitou a disputa de duas concepções de avaliação: uma de base qualitativa, voltada para a supervisão do funcionamento institucional das IES, cuja ênfase recaía sobre a mensuração de desempenho e resultado dos cursos e instituições; e outra de base qualitativa, com foco nas atividades e processos acadêmicos, a fim 
de suplantar fragilidades e desenvolver as potencialidades das instituições. Esse confronto resultou em dois movimentos políticos e epistemológicos, um voltado ao controle da qualidade pela supervisão do desempenho e da eficiência, e outro pautado na produção da qualidade e da melhoria institucional construída coletivamente pelos agentes da educação superior. Barreyro e Rothen (2006) sintetizam essas concepções de avaliação em duas vertentes: a primeira como atividade de controle fundamentada em uma lógica burocrático-formal, e outra de princípio formativo/emancipatório estruturada sobre uma lógica acadêmica voltada à autorregulação e à melhoria institucional - esta última intimamente ligada à noção de 'review and development'.

Tal dualidade de perspectivas pode ser percebida ao se analisar a legislação referente ao tema. No final do século XX, uma série de atos legislativos foram publicados com vistas a estabelecer diretrizes para o processo de avaliação institucional centrada na eficiência, na produtividade, na prestação de contas e no controle de desempenho pelo Estado. Em 1995, por exemplo, a Lei № 9.131 instituiu o Exame Nacional de Cursos, popularmente conhecido como Provão, cujo objetivo era avaliar os cursos de ensino superior a partir de provas aplicadas aos alunos concluintes da graduação, a cada ano. A implantação desse instrumento, como de outros, é contemporânea à aprovação da Lei de Diretrizes e Bases da Educação Nacional (LDBN), Lei $\mathrm{N}^{\circ} 9.394 / 96$.

As transformações inseridas pela LDBN e posteriormente regulamentadas provocaram a expansão do ensino superior privado no Brasil (BARREYRO; ROTHEN, 2006). Tais atos normativos atendiam ao previsto no inciso III do art. 206 da Constituição Federal de 1988, que admite a coexistência de instituições públicas e privadas de ensino, bem como o pluralismo de ideias e de concepções pedagógicas. Segundo dispõe o art. 209 da Lei, o ensino é livre à iniciativa privada atendidas as seguintes condições (BRASIL, 1988): "I - cumprimento das normas gerais da educação nacional; II - autorização e avaliação de qualidade pelo poder público".

Como consequência dessa normatização, a privatização do ensino e a pluralidade institucional no século XXI constituem uma realidade que não pode ser negada e tampouco negligenciada ao se analisar a educação brasileira.

Em seu art. 19, a LDBN refere às categorias administrativas públicas e privadas das instituições de ensino e, no art. 20, classifica as instituições privadas da seguinte forma (BRASIL, 1996):

Art. 20. As instituições privadas de ensino se enquadrarão nas seguintes categorias; I - particulares, em sentido estrito, assim entendidas as que são instituídas e mantidas por uma ou mais pessoas físicas ou jurídicas do direito privado que não apresentem as características dos incisos abaixo: 
II - comunitárias, assim entendidas as que são instituídas por grupos de pessoas físicas ou por uma ou mais pessoas jurídicas, inclusive cooperativas educacionais, sem fins lucrativos, que incluam na sua entidade mantenedora representantes da comunidade. III - confessionais, assim entendidas as que são instituídas por grupos de pessoas físicas ou por uma ou mais pessoas jurídicas que atendem a orientação confessional e ideologia específicas e ao disposto no inciso anterior;

IV - filantrópicas, na forma da lei.

Por sua vez, o art. 46 da mesma Lei determina que "a autorização e o reconhecimento de cursos, bem como o credenciamento de instituições de educação superior, terão prazos limitados, sendo renovados, periodicamente, após processo regular de avaliação" (BRASIL, 1996). O ensino privado depende, portanto, de autorização do poder público para ser exercido e está sujeito às normas gerais da educação e à avaliação da qualidade.

Em 2004, foi instituído o Sistema Nacional de Avaliação da Educação Superior SINAES pela Lei $N^{0} 10.861$, com a finalidade de favorecer a construção de um sistema nacional de avaliação da educação superior de articulação entre o caráter de regulação e controle do Estado com a avaliação formativa relacionada a juízos de valor e mérito, a fim de propagar a qualidade e as capacidades de emancipação das instituições educativas (PEIXOTO, 2009).

A aprovação da Lei pode ser considerada um marco na história das políticas públicas da educação superior, pois, conforme sinalizam Barreyro e Rothen (2006), essa medida organizou a formulação de um Sistema de Avaliação, rompendo com a publicação isolada de instrumentos através de leis, portarias, decretos, além de posicionar a avaliação como meio de melhoria da qualidade vinculada a valores e à valorização da educação superior como bem público.

O SINAES tem por finalidade a melhoria da qualidade da educação superior, a orientação da expansão da sua oferta, o aumento permanente da sua eficácia institucional e efetividade acadêmica e social, e especialmente a promoção do aprofundamento dos compromissos e responsabilidades sociais das instituições de educação superior, por meio da valorização de sua missão pública, da promoção dos valores democráticos, do respeito à diferença e à diversidade, da afirmação da autonomia e da identidade institucional. (PORTARIA MEC n. 2.051/04, art. $1^{\circ}$ apud ZAINKO, 2008, p. 830).

Dessa forma, a Lei $N^{\circ} 10.861 / 2004$ inaugura uma nova perspectiva para o tema da avaliação institucional da educação superior, fazendo com que esta passe a ser entendida como política educacional que ultrapassa os mecanismos restritos de supervisão e controle estatal de cursos e instituições, sem, no entanto, abandonar essa função, para atingir também a esfera de emancipação e responsabilidade social das IES, contribuindo, de modo mais amplo, com um rol de políticas públicas de educação superior. 


\section{A autoavaliação institucional e o diálogo nas organizações de ensino superior no Brasil}

Dentro da abordagem mais sistêmica das políticas de avaliação da educação superior instituída pelo SINAES, a autoavaliação passa a configurar-se como um dos instrumentos da avaliação institucional. Para coordenar esse processo de autoavaliação, a Lei define que cada instituição crie uma Comissão Própria de Avaliação - CPA, cuja representatividade conte com agentes da sociedade civil e de todos os segmentos da comunidade organizacional. Síveres (2016, p. 28) compreende "que o projeto educativo é essencialmente um processo dialogal, que se estabelece na relação entre sujeitos, que mediados pela realidade e pelos fenômenos, buscam articular o ser e o agir para promover uma educação humanizadora e libertadora".

Ao permitir e envolver a participação de diversos agentes do ambiente institucional, podemos considerar a CPA e o processo de autoavaliação conduzido por ela como um caminho de construção do diálogo entre os diferentes atores sociais que constituem o corpo organizacional e os agentes externos a essa comunidade. O conceito de diálogo aqui entendido está ancorado ao que nos apresenta Síveres (2016, p. 15-16):

[...] o diálogo não é apenas uma cadeia produtiva de informações, nem uma rede de comunicações e, nem tampouco, um sistema de tecnologias de comunicação. Mesmo contando com estas instrumentalidades, o diálogo é um princípio instituidor da existência humana, uma mediação para a construção do conhecimento e, portanto, uma possibilidade de contribuir com as finalidades do processo educativo.

Dirigida pela CPA, a autoavaliação propõe realizar um estudo reflexivo orientado por roteiro geral e indicadores específicos, definidos em base nacional, com o objetivo de identificar vias e recursos que possibilitem a melhoria da IES nas suas dimensões pedagógica, administrativa, política e técnico-científica (INEP, 2015).

Ao apresentar esse novo enfoque do processo avaliativo, a autoavaliação institucional tende a carregar condições de favorecer "a construção de uma cultura de avaliação, com a qual a comunidade interna se identifique e se comprometa" (PEIXOTO, 2009, p. 14).

Aportamos aqui o conceito de cultura organizacional ao que enuncia Schein (2017), ao esclarecer que esta é o resultado das experiências de aprendizagem compartilhadas por determinado grupo, que levam a suposições básicas, divididas e assumidas como verdadeiras pelos membros da organização em relação aos problemas de adaptação externa e de integração interna. Essas atitudes, normas e valores que se tornam comuns a todos passam a formar um padrão de suposições básicas compartilhadas (SCHEIN, 2017).

A cultura da avaliação indicada por Peixoto (2009) e a finalidade maior a que se designa o processo de autoavaliação institucional conduzido pela CPA podem ser associadas ao 
pensamento de Brito (2016), que ressalta a relevância da participação consciente de todos os envolvidos no processo organizacional para a efetividade e para o sucesso do projeto educativo que se propõe desenvolver. Outrossim, a prática da autoavaliação institucional pode, portanto, mobilizar a comunidade acadêmica em torno de um processo coletivo de engajamento e comprometimento quanto à melhoria de seus processos. Segundo Brito (2016), a percepção dialógica do processo educacional concebe o diálogo como fator primordial para as relações entre os agentes envolvidos nesse processo.

Esse fazer multilateral, composto pelas variadas visões, perspectivas, impressões e vivências dos distintos agentes que atuam no cotidiano institucional, contribui com a construção de uma identidade institucional e de um planejamento estratégico que vislumbre a eficiência e a eficácia organizacional, tendo-se em mente o ensino de qualidade que favoreça a garantia da aprendizagem dos estudantes. Nesse sentido, é importante destacar que, ao estabelecer indicadores que balizam as ações pedagógicas, administrativas, científicas e políticas das IES, o processo de autoavaliação institucional caminha em direção à garantia de padrão de qualidade do ensino, assegurada no inciso VII do art. 206 da Constituição Federal.

Todavia, ressaltamos que o simples ato de se proporcionar espaços comunicativos e de expressão, como é o caso da CPA, não é suficiente para assegurar o efeito gerador de um processo dialógico. Considerando ainda a perspectiva dialética do diálogo, a simples constatação de que uma instituição conte com processos organizacionais bem definidos e possua um sistema de normas e sistematizações de seu processo avaliativo não é garantia de que essa dinâmica contemple os aspectos de reciprocidade, alteridade e responsabilidade - pilares que fundamentam o conceito de diálogo segundo Buber - inerentes ao processo dialógico do fazer educativo. De acordo com a filosofia buberiana, a reciprocidade corresponde ao processo que transforma comunicação em comunhão por meio da interação humana; a alteridade consiste no movimento básico do diálogo que sai de si e volta-se ao outro; e a responsabilidade busca responder verdadeiramente ao outro (SÍVERES, 2016). Portanto, para que esses três fundamentos integrem uma relação dialógica, vimos necessário desenvolver a consciência coletiva sobre o que se constrói e envolver verdadeiramente os integrantes de determinado grupo social em uma práxis permanente e efetiva de ação-reflexão-ação.

\section{O papel da Comissão Própria de Avaliação como agente de construção dialógica nas IES}

A Lei $\mathrm{N}^{0} 10.861 / 2004$, em seu art. 11, determina que a CPA seja composta por uma comissão representativa de todos os segmentos da comunidade acadêmica, como também por 
membros da sociedade civil organizada. No entanto, fica a cargo dos órgãos colegiados superiores das instituições a definição do número de integrantes, a forma de organização e o modo de funcionamento da Comissão, conforme o porte, as características e as experiências prévias de avaliação da IES. Tendo em vista o grau de autonomia atribuído pela Lei às instituições para a estruturação das CPA's, pressupõe-se a existência de diversificados modelos de organização e funcionamento de tais comissões, como sugere Peixoto (2009).

Este tópico merece destaque, uma vez que evidencia o aspecto participativo e democrático da CPA, no sentido em que a contribuição de diferentes atores do universo institucional ajuda a compor um panorama da organização, com vistas a perceber fragilidades, potencialidades, avanços, retrocessos, necessidades, expectativas, interesses e demandas da realidade institucional.

Contudo, ponderamos ser salutar e necessário refletir de forma crítica também sobre os entraves enfrentados pelas IES para efetivação da CPA e consequente realização da autoavaliação. Segundo o que nos aponta Zainko (2008, p. 831), as dificuldades muitas vezes estão ancoradas "em problemas políticos e na escassez de pessoal familiarizado com a questão, insuficiência de discussões internas e nas dificuldades para a realização da autoavaliação”. Peixoto (2009), por sua vez, cita Andriola (2005) ao descrever como desafios à CPA a necessidade de sensibilizar a comunidade interna para o processo avaliativo e a importância de incentivar a mobilização e a participação dos atores institucionais nessa direção. Esses são pontos que devem ser considerados e encarados por gestores educacionais ao enfrentarem o desafio de fazer com que a CPA sirva de ponte para o diálogo entre a comunidade acadêmica e a gestão das instituições de ensino.

O planejamento de qualquer instituição é uma peça-chave de gestão que, além de contribuir para a definição dos objetivos e metas a serem alcançados, permite que as ações planejadas possam ser acompanhadas e assim ajustadas à medida que, sendo necessário, visem atingir às expectativas dos destinatários de funcionamento da IES: a comunidade acadêmica. Como afirma Brito (2016), o processo educativo deve ser baseado na construção conjunta do planejamento estratégico e da organização escolar a partir da interação dos atores da comunidade escolar. De acordo com Peixoto (2009, p. 21), “a ideia de que as instituições de ensino superior devam atribuir à avaliação institucional um grau elevado de importância no seu processo de gestão, tem estado presente na construção dos sistemas avaliativos que vêm sendo propostos para a educação superior brasileira”.

Nesse horizonte, elaborar pesquisas, sensibilizar para participação, coletar dados e produzir relatórios configura uma visão reducionista da importância da CPA, que pode contribuir muito para o desempenho de uma boa gestão da IES. Além destas atividades - que 
poderiam ser chamadas de automáticas -, a CPA pode criar um espaço permanente de diálogo entre a direção da IES e comunidade acadêmica, a fim de subsidiar a direção na elaboração do seu planejamento, de forma que potencialize suas ações voltadas aos reais interesses e necessidades apontados por professores e alunos.

Para além das atividades de rotina de elaboração e aplicação de pesquisas, será possível perceber que a CPA pode contribuir para o estabelecimento de um ambiente de diálogo entre direção da IES e comunidade acadêmica. Essa noção mais dialógica da CPA, ligada ao princípio formativo/emancipatório estruturada sobre uma lógica acadêmica voltada à autorregulação e à melhoria institucional, ao 'review and development', quando desenvolvida de forma transparente e fundada nas boas práticas, acarreta, consequentemente, na melhoria das redes relacionais dentro da intuição e, por conseguinte, na melhora do desempenho dos vários membros da IES. Em oposição a isso, a CPA fundamentada na atividade de controle, em uma lógica burocráticoformal, suscita medo e receio nos membros da comunidade acadêmica e, consequentemente, torna-se contraproducente para a eficácia de seus membros e da própria instituição. A CPA dialógica é usada para ajudar os membros da comunidade a terem o seu melhor; a CPA burocrático-formal é usada para instaurar controle, gerando uma cultura de desconfiança entre os membros da comunidade acadêmica e, assim, a ineficiência.

\section{Opções metodológicas}

Para realização da presente pesquisa foram selecionadas Instituições de Ensino Superior - IES do Distrito Federal, por critério de representatividade da concentração de IES numa única Unidade Federativa e extensão geográfica ${ }^{1}$. Foram definidas as IES privadas como recorte, setor onde se pode perceber, com maior evidência, a relevância do planejamento realizado por seus dirigentes. Não que as IES públicas não possuam seu planejamento, mas, por vezes, são afetadas pelas exigências da legislação do Estado, portanto menos evidenciado o papel dos dirigentes na sua concepção e aplicação.

Quanto à organização acadêmica ${ }^{2}$, foi descartada a Universidade, pois sendo única privada no DF, ficaria comprometido seu estudo comparativo. Foram retiradas também as Faculdades, por exercerem papel exclusivo do Ensino no tripé "Ensino-Pesquisa-Extensão", onde se percebe ser menos acentuado o papel da CPA no relacionamento entre a direção e

\footnotetext{
${ }^{1}$ Segundo dados do MEC/INEP, constam 97 IES registradas no Distrito Federal, das quais 78 são privadas, sendo 68 Faculdades, 9 são Centros Universitários e uma única Universidade.

${ }^{2}$ A Organização Acadêmica das IES, definida pelo MEC/INEP, possui as seguintes categorias: Faculdade, Centro Universitário, Institutos Federais, Universidade e Escola de Governo.
} 
comunidade acadêmica. Restaram então os nove Centros Universitários, os quais foram contatados. Deste total, dois aceitaram o convite para a realização da entrevista semiestruturada e outros quatro acataram a participação com preenchimento do questionário eletrônico, resultando, assim, em seis IES do universo de nove, portanto dois terços, compreendidos como representativo para tal finalidade da pesquisa acadêmica.

As entrevistas semiestruturadas foram realizadas presencialmente com respectivos coordenadores da CPA, entre os dias 23 e 27 de setembro de 2019, na sede de cada IES, precedidas da apresentação e assinatura do Termo de Aceite, conforme estabelece legislação do Comitê de Ética em Pesquisas - CEP, em sua Resolução CNS N 196/96. O roteiro para as entrevistas era composto por quatro questões, a saber:

a) Fale sobre a composição e funcionamento da CPA, sua rotina de reuniões, elaboração e aplicação das pesquisas junto à comunidade acadêmica.

b) Historicamente, qual a participação da comunidade acadêmica nas respostas às pesquisas da CPA? Há algo que possa ser exemplificado como estratégia de estímulo à participação?

c) Descreva como são coletados e tratados os dados das pesquisas se há algum sistema de apuração das respostas, se a CPA conta com alguém com conhecimento estatístico para análise das respostas e, em síntese, como são analisados e transformados em relatório, apresentado à direção da IES.

d) Relate como se dá a apresentação formal dos relatórios à direção da IES e quais encaminhamentos são dados (ou não) às demandas apontadas nas pesquisas.

e) O questionário eletrônico foi elaborado com 11 questões objetivas, usando a plataforma MS-OFFICE 365, com o aplicativo MS-FORMS, cujo link $U R L^{3}$ foi testado por respondentes voluntários e posteriormente disponibilizado aos membros de cada CPA dos Centros Universitários do DF. A distribuição do link, tanto por e-mail como por mensagem de aplicativo WhatsApp, se deu a partir de rede de contatos existentes entre os procuradores institucionais das IES no DF e um dos pesquisadores.

O preenchimento do questionário eletrônico ocorreu no período de 23 de setembro a 4 de outubro de 2019, com identificação opcional do respondente, garantindo, assim, a preservação de sua identidade. Ao total, foram coletadas 35 respostas, das quais três foram descartadas por preenchimento em duplicidade, restando, portanto, 32 respostas válidas para análise dos dados da presente pesquisa.

A estatística descritiva se deu pela exportação da base de dados do formulário para planilha MS-EXCEL, com respectiva elaboração dos gráficos e tabelas. Entendemos como

\footnotetext{
${ }^{3}$ Link URL disponibilizado para preenchimento do questionário eletrônico: https://forms.office.com/Pages/ResponsePage.aspx?id=oTQBh6gK90yrHyym3FVw7aCqeiRygJdNmwfgkV7F glJUOTNaNEE5M0JBNTNVT01HT1JBSEgyN1VQQS4u
} 
dispensável o uso de outros sistemas estatísticos mais elaborados, tanto pela simplicidade das questões como pelo número de respostas.

\section{Percurso metodológico - relacionando teoria e empiria}

A coleta dos dados para a presente pesquisa se deu essencialmente em dois pilares: a) pelas respostas às duas entrevistas semiestruturadas, com indicação de exemplos, apontamento da correlação entre os instrumentos de coleta dos dados da CPA, a produção dos relatórios e o uso destes na elaboração do planejamento da instituição; b) pelas 32 respostas ao questionário eletrônico, composto por 11 questões objetivas, respondidas por membros da CPA, sendo estes representantes discentes, docentes, técnico-administrativos e representantes da sociedade civil.

A primeira IES onde foi realizada a entrevista é um Centro Universitário tradicional no DF, que iniciou suas atividades em 1977 com oferta da educação básica e que, desde 2006, atua na Educação Superior. Possui quatro unidades de ensino da educação superior e três unidades da educação básica, e atua em quatro Regiões Administrativas do DF, tanto com ensino presencial quanto com EAD. Nela, a CPA é formada por uma coordenação geral, que abrange as unidades instaladas em Taguatinga, Ceilândia, Guará e Sobradinho. Em cada uma das unidades há ainda a composição dos demais representantes (docente, discente, técnicoadministrativo e sociedade civil). As reuniões ordinárias ocorrem semestral ou extraordinariamente, quando convocadas. A aplicação das pesquisas para alunos e professores se dá por meio eletrônico, no sistema "Blog do Aluno", bem como pelo portal ERP para os colaboradores. A cada ciclo avaliativo semestral, o formulário permanece acessível por 30 dias e a coordenação acompanha diariamente o número de respondentes que completam as respostas (sem identificação do respondente). Além desta, a CPA aplica também outras que contribuem para o bom andamento da gestão da IES, a saber: a) pesquisas de perfil socioeconômico do candidato ao ingresso no vestibular; b) pesquisa de satisfação no atendimento do Núcleo de Práticas Jurídicas; e c) pesquisa de empregabilidade e carreira do egresso.

O trabalho de sensibilização para participação da comunidade acadêmica nas pesquisas é feito desde o ingresso do aluno no $1^{\circ}$ período, com presença em sala de aula, reunião semestral no auditório, através do "Blog do Aluno", no site institucional da IES e através da conscientização dos coordenadores de curso e professores. O histórico de participação é superior a $50 \%$ entre professores e alunos e chega a atingir $80 \%$ dentre os colaboradores técnico-administrativos. Tais percentuais são considerados como muito bons pela coordenação. 
Como o preenchimento é eletrônico, o sistema chamado "Phidelis 360" coleta e mensura automaticamente dados e gera gráficos pré-definidos para análise na coordenação da CPA. Com o apoio de uma assistente administrativa, a coordenação faz a leitura, análise dos dados e elabora os relatórios. A CPA não conta com colaborador especialista em estatística ou similar. Por possuir estrutura centralizada da CPA de todas as unidades educacionais, análises comparativas entre as unidades e de série histórica são possíveis de serem compostas para apresentação à direção da IES. Os resultados das análises, gráficos e relatórios são amplamente divulgados no "Blog do Aluno", em cartazes pela IES, especialmente nos locais onde melhorias foram feitas a partir das demandas dos alunos. Já se vê a cultura de os alunos procurarem o cartaz "Você participou da autoavaliação e nós atendemos [tal item de melhoria]". É realizado encontro anual com todas as lideranças do Grupo Educacional, oportunidade em que são elaborados os planejamentos de ação para o ano seguinte, todos feitos à luz dos relatórios produzidos pela CPA. Este momento é destacado com grande ênfase de importância pela coordenação da Comissão, pois compreende que é a colaboração desta para o diálogo entre as expectativas da comunidade acadêmica e a direção da IES na elaboração do seu planejamento.

Além da divulgação dos resultados em gráficos, um trabalho detalhado e minucioso é feito para elaboração do relatório que é passado à direção da IES, com a transcrição fiel de todos os apontamentos feitos pelos alunos e professores, pois cada resposta textual é avaliada e tratada pela direção, quer seja para busca de melhorias ou para análise dos resultados aplicados em anos anteriores. Nesta oportunidade junto à direção da IES, aplica-se a ferramenta do PDCA, onde são avaliadas as implementações em ciclos anteriores, para, então, retomar o ciclo de retroalimentação, sempre em busca de melhorias.

Com base nos relatos e evidências apresentados pela coordenação da CPA da primeira IES, pode-se inferir que há efetivo trabalho de colaboração da CPA na construção do diálogo entre comunidade acadêmica e Direção da IES.

A segunda IES onde foi realizada a entrevista é também um Centro Universitário, em processo final de consolidação da recém transformação de sua organização acadêmica. Iniciou suas atividades em 1987 diretamente na Educação Superior, possui um único campus, situado em uma Região Administrativa do DF, e atua tanto no ensino presencial como no EAD.

Por se tratar de uma IES com uma única unidade educacional, todas as atividades de coordenação e representantes da CPA concentram na sede da direção da IES, o que facilita sobremaneira o trabalho de planejamento, reuniões e aplicação das pesquisas. A composição da CPA é paritária, conforme determina a legislação do SINAES, ampliada com dois representantes de cada segmento: docente, discente, técnico-administrativo e sociedade civil, 
formada assim por nove componentes, mais uma assistente administrativa e um jovem aprendiz ligado à TI, que colaboram com as rotinas burocráticas e de interação com os sistemas da IES. Há uma rotina de reuniões mensais que, na maioria das vezes, conta com mais de $50 \%$ dos membros. São aplicadas duas avaliações anuais. No $1^{\circ}$ semestre, a avaliação é voltada aos alunos e professores, com aspectos acadêmicos e de ações das coordenações de curso. No $2^{\circ}$ semestre são acrescentadas questões ligadas à infraestrutura e participam da pesquisa todos os colaboradores da IES e os alunos das disciplinas em EAD, os quais também avaliam os cursos em todos os aspectos (disciplinas, conteúdo, metodologia, professores, tutores, sistema AVA, infraestrutura etc.). A percepção da CPA em toda a comunidade acadêmica tem sido positiva e crescente, sobretudo nos últimos dois anos, quando houve mudança na coordenação da Comissão e foi adotado o slogan "CPA Portas Abertas", em que sempre há alguém da CPA em expediente na sala, sempre aberta, pronta para receber qualquer aluno que queira apresentar suas sugestões, demandas e/ou contribuições.

O trabalho de sensibilização para participação das pesquisas é intenso. São feitas campanhas constantes de divulgação dos ciclos de avaliação, reuniões são realizadas nos setores administrativos da IES, bem como junto aos representantes de turmas, em todos os cursos e turnos. A adesão é expressiva, atingindo $80 \%$ dos alunos, $90 \%$ dos professores e acima de $95 \%$ do corpo técnico-administrativo. Nas reuniões com representantes de turma são recebidas informações sobre a percepção dos colegas na realização das pesquisas e tem sido crescente a devolutiva do que percebem como melhorias. A devolutiva aos alunos sobre ações resultantes das pesquisas é feita por cartazes e pelo selo "Você avaliou, a CPA mudou", aplicado nas peças de divulgação. Exemplo recente pode ser citado com os computadores da biblioteca, alvo de constantes críticas por seu mal funcionamento. A CPA apontou estas demandas e a direção compreendeu a importância de investir no parque tecnológico e renovou todos os equipamentos. A percepção de pertença dos alunos foi manifestada em registros de elogios junto à ouvidoria. Outra ação notável foi a reforma do Hospital Veterinário, cuja melhoria foi percebida não só por alunos e professores, mas também pela comunidade externa atendida por aqueles serviços.

Desde 2017, a coleta dos dados para as pesquisas evoluiu do formato "amador", adotado com o Google Forms, para o formato "profissional" integrado ao sistema de ERP acadêmico adotado com o TOTVS. Nas edições anteriores, levava-se meses para apuração e tratamento dos dados, o que hoje é feito em poucos dias ou de forma on-line, acompanhado da sala da CPA. Além de agilidade e integração, o sistema garante total sigilo do respondente, o que é indispensável para a confiança e credibilidade de todo o processo de autoavaliação. Não há, na equipe da CPA, o apoio de profissional com domínio em estatísticas, apenas uma colaboradora 
que domina o Excel e contribui na extração dos dados com filtros e totais, gerando os gráficos para análise, a qual é feita pela coordenação da CPA. Um dos gráficos de grande relevância utilizado é o do "ranking”, onde são elencadas as questões de maior impacto e relevância. Para este são voltadas a atenção e prioridades da Direção da IES e das coordenações de cursos.

Uma vez analisados os dados coletados e produzidos os gráficos, o relatório final é apresentado à direção da IES, em momento conjunto desta com a mantenedora, para que possam ser tratadas, ao mesmo tempo, as ações que dependem da instância de cada um. Em momento à parte é feita reunião específica com a Pró-Reitoria acadêmica com coordenadores (para tratar dos aspectos acadêmicos da pesquisa) e outra com a Pró-Reitoria administrativa e líderes dos setores (para tratar dos aspectos administrativos da pesquisa). A partir destas reuniões são elaborados os planos de ação corretivas que, colocados à disposição da CPA, são acompanhados em suas etapas de execução e apresentação aos alunos sobre os seus desdobramentos. A CPA não só atua na coleta dos dados, mas também no acompanhamento da execução e devolutiva das ações provenientes destes, o que pode ser compreendido como efetivo papel de construção do diálogo entre direção da IES e comunidade acadêmica. Exemplo recente está ligado à reclamação de alunos e professores no acesso ao estacionamento. Uma única guarita para acesso e pagamento dos veículos gerava grandes filas e incômodo para os usuários. O relatório provocou a revisão no contrato com a empresa prestadora de serviço para ampliação dos pontos de acesso e pagamento, e a ação foi divulgada aos usuários, que puderam acompanhar o cronograma de execução das melhorias. Este é um papel da CPA relatado como relevante pela coordenação, que entende a sua importância na construção do diálogo entre comunidade acadêmica e a direção da IES. Nas palavras da coordenação, "a CPA dá voz a todos os atores da comunidade acadêmica sobre o que pensam, veem e sentem".

Por sua vez, o questionário eletrônico aplicado gerou 32 respostas válidas, cujos dados são analisados a seguir.

Gráfico 1 - Representatividade na CPA

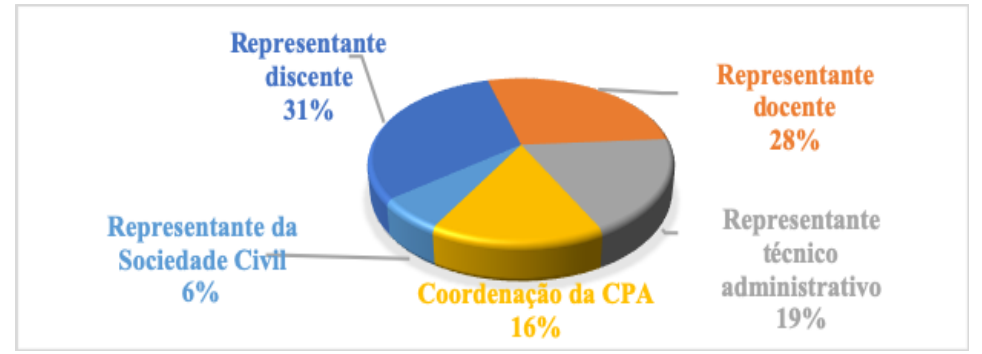

Fonte: Elaboração dos autores com base nas respostas ao questionário eletrônico da pesquisa (2019). 
A participação dos respondentes contou com a representatividade de todos os seguimentos. Merece destaque a adesão dos alunos, com $31 \%$, podendo-se inferir que percebem credibilidade e importância na CPA.

\section{Gráfico 2 - Tempo de Participação na CPA}

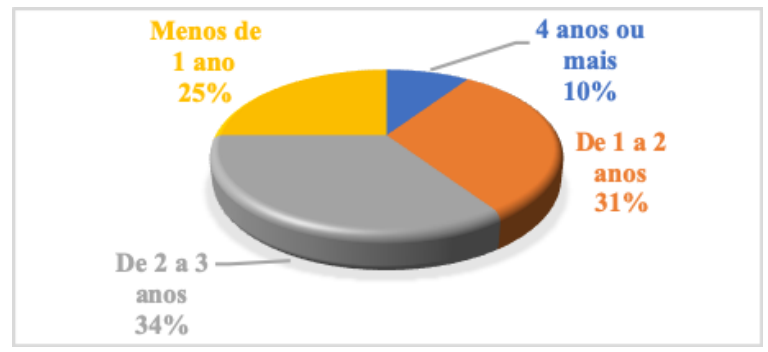

Fonte: Elaboração dos autores com base nas respostas ao questionário eletrônico da pesquisa (2019).

O tempo de participação de cada componente na CPA não possui uma predominância. Um em cada quatro tem menos de um ano, apenas três possuem quatro anos ou mais, e dois terços participam da CPA entre um e três anos. A rotatividade pode ser atribuída ao tempo de curso, para os discentes, e à pouca estabilidade docente no mercado privado. A maior parte dos respondentes com quatro anos ou mais está concentrada nas coordenações, o que, ao menos, pode garantir continuidade nos trabalhos realizados.

\section{Gráfico 3 - Frequência das Reuniões}

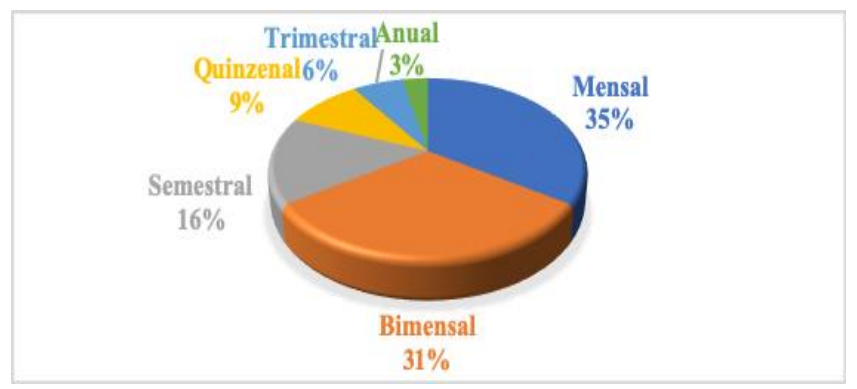

Fonte: Elaboração dos autores com base nas respostas ao questionário eletrônico (2019).

O tópico acima apresenta uma situação curiosa, pois respondentes da mesma IES apontaram constâncias diferentes, o que leva a crer que, embora assinale haver comunicação prévia para realização da reunião, o respondente se baseou na sua participação, e não na frequência da realização. O dado traz que dois em cada três confirmam que as reuniões ocorrem a cada dois meses no máximo, o que pode ser considerado salutar para o bom andamento dos trabalhos, ainda que a frequência das pesquisas venha a ser semestral. 
Tabela 1 - Bloco de questões relativas ao funcionamento das reuniões

\begin{tabular}{l|l|l|l|l|l}
\hline & Sempre & $\begin{array}{l}\text { Maioria } \\
\text { das vezes }\end{array}$ & $\begin{array}{l}\text { Meio a } \\
\text { meio }\end{array}$ & Raramente & Nunca \\
\hline Há convocação prévia com indicação da pauta. & $97 \%$ & - & $3 \%$ & - & - \\
\hline A pauta da reunião é seguida. & $97 \%$ & - & $3 \%$ & - & - \\
\hline Há registro das reuniões em ata. & $56 \%$ & $38 \%$ & $6 \%$ & - & - \\
\hline Há envio da ata aos participantes após as reuniões. & $44 \%$ & $3 \%$ & $28 \%$ & $25 \%$ & - \\
\hline $\begin{array}{l}\text { A ELABORAÇÃO das pesquisas conta com a } \\
\text { colaboração de todos os membros da CPA. }\end{array}$ & $44 \%$ & $3 \%$ & $25 \%$ & $28 \%$ & - \\
\hline $\begin{array}{l}\text { A SENSIBILIZAÇÃO para participação da } \\
\text { comunidade acadêmica, conta com a participação de } \\
\text { todos os membros da CPA. }\end{array}$ & $47 \%$ & $28 \%$ & $22 \%$ & - & $3 \%$ \\
\hline $\begin{array}{l}\text { A APLICAÇÃO das pesquisas conta com a } \\
\text { participação de todos os membros da CPA. }\end{array}$ & $59 \%$ & $35 \%$ & $3 \%$ & - & $3 \%$ \\
\hline $\begin{array}{l}\text { A ANÁLISE DAS RESPOSTAS das pesquisas conta } \\
\text { com a participação de todos os membros da CPA. }\end{array}$ & - & $16 \%$ & $36 \%$ & $32 \%$ & $16 \%$ \\
\hline
\end{tabular}

Fonte: Elaboração dos autores com base nas respostas ao questionário eletrônico da pesquisa (2019).

O zelo no registro em ata está preservado quando $94 \%$ dos respondentes afirmam que são realizados na maioria das vezes ou sempre. O meio adotado pela coordenação para convocar previamente a realização das reuniões pode ser considerado eficaz, já que $97 \%$ responderam que sempre ocorre. Também merece destaque a condução realizada pela coordenação, pois 97\% dos respondentes apontam que a pauta é cumprida, imprimindo assim seriedade e organização na condução deste importante trabalho dentro da IES.

Menos eficiente que o trato dado à convocação prévia e ao cumprimento da pauta, refere-se ao envio da ata. Este dado não chega a comprometer o trabalho da Comissão, mas há aqui uma oportunidade de melhoria por parte dos coordenadores, já que 53\% assinalam que esse procedimento é adotado meio a meio ou raramente.

No que tange à preparação das pesquisas, apenas $44 \%$ dos respondentes confirma haver participação de todos da CPA. A falta de participação não significa, necessariamente, que a pesquisa seja mal elaborada, mas há chance de melhoria neste ponto.

Os componentes da CPA se sentem menos participantes quando se trata da análise dos resultados. Apenas 16\% apontam maioria das vezes. Todos os demais relatam menor participação, chegando a constar 4 respostas como nunca terem participado da análise dos dados. Este é um fato mais crítico que a elaboração, pois o resultado do relatório deve, a princípio, representar fielmente a percepção dos respondentes, para que na análise não haja qualquer interferência ou viés tendencioso que possa comprometer a fidelidade das respostas. 
Tabela 2 - Bloco de questões relativas ao tratamento dos dados das reuniões

\begin{tabular}{|c|c|c|c|c|c|}
\hline & $\begin{array}{l}\text { Concordo } \\
\text { totalmente }\end{array}$ & $\begin{array}{l}\text { Concordo } \\
\text { parcialmente }\end{array}$ & $\begin{array}{l}\text { Não concordo } \\
\text { nem discordo }\end{array}$ & $\begin{array}{l}\text { Discordo } \\
\text { parcialmente }\end{array}$ & $\begin{array}{l}\text { Discordo } \\
\text { totalmente }\end{array}$ \\
\hline $\begin{array}{l}\text { Os dados coletados nas pesquisas } \\
\text { são fidedignos à percepção dos } \\
\text { respondentes. }\end{array}$ & $44 \%$ & $47 \%$ & $9 \%$ & 工 & 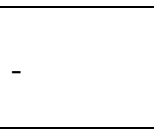 \\
\hline $\begin{array}{l}\text { Há isenção da CPA na análise das } \\
\text { respostas (quer sejam positivas } \\
\text { ou negativas). }\end{array}$ & $88 \%$ & $12 \%$ & - & - & - \\
\hline $\begin{array}{l}\text { Os relatórios produzidos são } \\
\text { elaborados com olhar crítico e } \\
\text { propositivo (buscar melhorias, } \\
\text { sem juízo de valor). }\end{array}$ & $94 \%$ & $6 \%$ & - & - & - \\
\hline $\begin{array}{l}\text { O extrato (resumo) do relatório é } \\
\text { publicado amplamente, para } \\
\text { conhecimento da Comunidade } \\
\text { Acadêmica. }\end{array}$ & $88 \%$ & $12 \%$ & - & - & - \\
\hline $\begin{array}{l}\text { O inteiro teor do relatório é } \\
\text { apresentado à direção da IES, } \\
\text { com transparência e isenção (sem } \\
\text { protecionismo ou tenência de } \\
\text { favorecimentos). }\end{array}$ & $84 \%$ & $16 \%$ & - & - & - \\
\hline $\begin{array}{l}\text { A direção da IES realiza reunião } \\
\text { com a CPA para recebimento do } \\
\text { relatório de avaliação. }\end{array}$ & $62 \%$ & $38 \%$ & - & - & - \\
\hline $\begin{array}{l}\text { A direção da IES recebe, } \\
\text { internaliza e trabalha suas ações } \\
\text { tomando por base os resultados } \\
\text { do relatório da CPA. }\end{array}$ & $97 \%$ & $3 \%$ & - & - & - \\
\hline $\begin{array}{l}\text { A direção da IES promove ações } \\
\text { de respostas à Comunidade } \\
\text { Acadêmica, a partir dos temas } \\
\text { apontados na pesquisa da CPA. }\end{array}$ & $81 \%$ & $19 \%$ & - & - & - \\
\hline
\end{tabular}

Fonte: Elaboração dos autores com base nas respostas ao questionário eletrônico da pesquisa (2019).

Sobre o tratamento dos dados coletados, podemos verificar que não há predominância por sua absoluta credibilidade, já que 15 respondentes apontam concordar totalmente, e os demais 17 alegam concordar parcialmente ou não concordar nem discordar.

A credibilidade do resultado da pesquisa pode ser evidenciada quando 28 respondentes afirmam concordar totalmente com a isenção na análise dos dados e nenhum alegou discordar deste ponto. $\mathrm{O}$ fato de os participantes não participarem da análise não retira a credibilidade e seriedade do trabalho de seus pares. Após consolidação da análise dos dados e elaboração dos relatórios, $88 \%$ (maioria absoluta) apontam que os relatórios são amplamente divulgados para conhecimento da comunidade acadêmica, o que é um importante indicador de transparência.

Em resultado muito próximo à ampla divulgação, 27 respondentes afirmam que o inteiro teor do relatório é levado ao conhecimento da direção da IES. Partindo da afirmação que se trata de relatórios fidedignos na representação dos apontamentos dos respondentes, há que acreditar que um retrato da realidade da IES é levado ao conhecimento da direção. Ainda mais 
relevante do que os dados serem apresentados à direção, é a constatação de que estes são tratados pela gestão com seriedade e compromisso. Frustrante e infrutífero seria se o trabalho da CPA, após apresentado à direção, fosse descartado ou esquecido.

O mais expressivo e significativo para esta pesquisa pode ser constatado na última resposta, em que 26 respondentes afirmam concordar totalmente e seis respondentes concordam parcialmente que a direção da IES dá respostas à comunidade acadêmica após tratamento dos dados da pesquisa. Ao verificarmos que $100 \%$ dos respondentes consideram haver, por parte da gestão, devolutiva às questões levantadas pela comunidade acadêmica, podemos considerar que a CPA atua na construção do diálogo entre a direção da IES e a comunidade acadêmica.

\title{
Considerações
}

\begin{abstract}
O fenômeno da resposta é essencial à relação. Quem ouve se não é para responder? A experiência de receber a palavra e respondê-la é o âmago do "entre" ou a revelação vivida pela reciprocidade. Esta experiência vivida de um vínculo numa situação de apelo e resposta encerra para Buber o fenômeno da responsabilidade em seus dois sentidos: primeiro, como resposta e, segundo, como a "obrigação" de responder (ZUBEN apud BUBER, 2006, p. 33).
\end{abstract}

Dentro da tríade responsabilidade-reciprocidade-alteridade apresentada por Buber para caracterizar o diálogo, nos atrevemos, com este trabalho, a associá-la ao fenômeno desencadeado pela autoavaliação institucional, mediada pela CPA. Ao considerarmos o papel da CPA, quando imbuída do sentido maior de sua atuação, como elo entre a comunidade acadêmica e a direção das instituições de ensino, assumindo a esfera do "entre" na relação entre essas partes, ela passa a constituir-se como via dialógica. Na filosofia buberiana, é no "entre" que o fenômeno da resposta se manifesta e efetiva a experiência dialógica. E a responsabilidade, segundo Buber (2006), transcende o nível moral alcançando o nível ético da reciprocidade. Quando a CPA atinge a finalidade de estreitar a relação entre os entes envolvidos na dinâmica institucional e compromete-se a "receber a palavra e respondê-la" é possível que assuma o status ético e moral na construção dialógica da constituição organizacional.

A CPA e a autoavaliação institucional são exigências criadas pela Lei dos SINAES, mas que, para além de suas funções legais e regulatórias, podem contribuir para o desenvolvimento de uma relação dialógica entre a comunidade acadêmica e a gestão da IES. Entretanto, vimos que essa dimensão apenas será alcançada se tanto a comissão quanto a avaliação forem devidamente estruturadas de forma a atrair efetivamente o comprometimento e o engajamento de seus atores. Em contrapartida, na outra ponta, é fundamental que a direção institucional reconheça e valide a relevância desse mecanismo para subsidiar seu planejamento estratégico e 
aperfeiçoar seus processos, utilizando-se desses insumos para aprimorar suas potencialidades e superar suas fragilidades, no movimento de autoconhecer-se.

Constatamos, por meio da pesquisa realizada, que há efetivo trabalho da CPA na construção de um processo dialógico entre a comunidade acadêmica e a direção da IES, e isso é algo muito salutar para a instituição e para seus membros. Salutar porque pode encorajar o bem-estar e o bom desenvolvimento pessoal e profissional dos membros da instituição, e consequentemente para o próprio desenvolvimento da instituição. Diante da análise dos dados da pesquisa aqui apresentada, podemos perceber que a CPA contribui para o estabelecimento do diálogo, na perspectiva que nos aponta Síveres e Buber, entre a direção da IES e sua comunidade acadêmica, sendo relevante sua atuação para a construção e efetivação de uma cultura de avalição participativa, reflexiva, formativa e emancipatória. Esperamos com esta pesquisa, que parte de uma construção dos atores organizacionais, oferecer contributos da investigação sobre a administração educacional, conforme sugerido Dinis (2015).

\section{Referências}

BARREYRO, Gladys Beatriz; ROTHEN, José Carlos. "SINAES" contraditórios: considerações sobre a elaboração e implantação do Sistema Nacional de Avaliação da Educação Superior.

Educ. Soc., Campinas, v. 27, n. 96, p. 955-977, out. 2006. Disponível em:

http://www.scielo.br/scielo.php?pid=S0101-73302006000300015\&script=sci_abstract\&tlng=pt. Acesso em: 18 set. 2019.

BRASIL. Constituição da República Federativa do Brasil. Brasília, DF: Senado Federal: Centro Gráfico, 1988. Disponível em: http://www.planalto.gov.br/ccivil_03/constituicao/constituicao.htm. Acesso em: 20 set. 2019.

BRASIL. Lei no 9394, de 20 de dezembro de 1996. Estabelece as diretrizes e bases da educação nacional. Brasília, DF, 1996. Disponível em:

http://www.planalto.gov.br/ccivil_03/leis/19394.htm. Acesso em: 22 set. 2019.

BRASIL. Lei no 10.861, de 14 de abril de 2004. Institui o Sistema Nacional de Avaliação da Educação Superior - SINAES e dá outras providências. Brasília, DF, 2004. Disponível em: http://www.planalto.gov.br/ccivil_03/_ato2004-2006/2004/lei/110.861.htm. Acesso em: 20 set. 2019.

BRITO, Renato de Oliveira. A gestão participativa e o dialogismo percebido no processo educacional. In: SÍVERES. Luiz (org.). Diálogo - um princípio pedagógico. Brasília: Liber Livro, 2016. p. 157-174.

BUBER, Martin. Eu e Tu. 10. ed. rev. São Paulo: Centauro, 2006.

DINIS, Luís Leandro. Das teorias das organizações à organização das teorias: do mundo da gestão ao mundo da educação. Revista Brasileira de Política e Administração da 
Educação - Periódico científico editado pela ANPAE, [S.1.], v. 31, n. 1, p. 197-232, set. 2015. Disponível em: https://seer.ufrgs.br/rbpae/article/view/58925. Acesso em: 10 set. 2020.

INSTITUTO NACIONAL DE ESTUDOS E PESQUISAS EDUCACIONAIS ANÍSIO TEIXEIRA - INEP. SINAES: processo de avaliação 2015. Brasília, DF, 2015. Disponível em: http://inep.gov.br/processo-de-avaliacao. Acesso em: 1 out. 2019.

PEIXOTO, Maria do Carmo de Lacerda. A avaliação institucional nas universidades federais e as comissões próprias de avaliação. Avaliação, Campinas; Sorocaba, v. 14, n. 1, 2009. Disponível em: https://www.redalyc.org/articulo.oa?id=219114872002. Acesso em: 10 set. 2019.

SANDER, Benno. Administração da educação no Brasil: genealogia do conhecimento. Brasília: Liber Livro, 2007.

SCHEIN, Edgar Henry. Cultura organizacional e liderança. São Paulo: Atlas, 2017.

SÍVERES, Luiz. O diálogo na educação: uma relação entre o dialógico e a dialogicidade. In: SÍVERES. Luiz (org.). Diálogo - um princípio pedagógico. Brasília: Liber Livro, 2016. p. 15-30.

ZAINKO, Maria Amelia Sabbag. Avaliação da educação superior no Brasil: processo de construção histórica. Avaliação, Campinas; Sorocaba, SP, v. 13, n. 3, p. 827-831, nov. 2008. Disponível em: https://www.redalyc.org/pdf/2191/219114874012.pdf. Acesso em: 10 set. 2019. 